\title{
A UAV-BASED LOW-COST STEREO CAMERA SYSTEM FOR ARCHAEOLOGICAL SURVEYS - EXPERIENCES FROM DOLICHE (TURKEY)
}

\author{
K. Haubeck ${ }^{\mathrm{a}}$, T. Prinz ${ }^{\mathrm{b}}$ \\ ${ }^{\text {a }}$ Institute of Geography, Westfalian Wilhelms-University Münster, Germany - k.haubeck@uni-muenster.de \\ ${ }^{\mathrm{b}}$ Institute for Geoinformatics, Westfalian Wilhelms-University Münster, Germany - prinz@ uni-muenster.de
}

KEY WORDS: Archaeology, Application, DEM/DTM, Orthoimage, Close Range, UAV, Stereoscopic

\begin{abstract}
:
The use of Unmanned Aerial Vehicles (UAVs) for surveying archaeological sites is becoming more and more common due to their advantages in rapidity of data acquisition, cost-efficiency and flexibility. One possible usage is the documentation and visualization of historic geo-structures and -objects using UAV-attached digital small frame cameras. These monoscopic cameras offer the possibility to obtain close-range aerial photographs, but - under the condition that an accurate nadir-waypoint flight is not possible due to choppy or windy weather conditions - at the same time implicate the problem that two single aerial images not always meet the required overlap to use them for $3 \mathrm{D}$ photogrammetric purposes. In this paper, we present an attempt to replace the monoscopic camera with a calibrated low-cost stereo camera that takes two pictures from a slightly different angle at the same time. Our results show that such a geometrically predefined stereo image pair can be used for photogrammetric purposes e.g. the creation of digital terrain models (DTMs) and orthophotos or the 3D extraction of single geo-objects. Because of the limited geometric photobase of the applied stereo camera and the resulting base-height ratio the accuracy of the DTM however directly depends on the UAV flight altitude.
\end{abstract}

\section{INTRODUCTION}

Archaeology offers a wide field of possible applications for Unmanned Aerial Vehicles (UAVs). Because of their small weight and compact dimensions and the possibility to collect data without having ground based physical access to areas of interest, they are very well suited for the usage at archaeological excavation sites. Traditionally the documentation in Archaeology is based on accurate mapping by hand drawings or by using terrestrial survey instruments like theodolites or laser scanner. Both methods are extremely time-consuming and costintensive, so consequently one important methodological issue is the documentation of historic geo-structures and -objects by close-range aerial photography. This can be achieved by using UAV-attached digital small frame cameras. The common UAV remote sensing system set-up is usually driven by the idea of high flexibility, efficiency and economical aspects and even more important: to overcome the limitation of the restricted payload by an optimal sensor set up. Consequently lightweighted monoscopic consumer digital cameras (which are often not calibrated) are being used for image acquisition and geo-object mapping. In order to be able to use such individual images for $3 \mathrm{D}$ photogrammetric purposes, two corresponding images require an overlap of at least 60\% (Kraus, 2007).

Especially if the excavation site is located at an unsheltered and exposed spot, unstable and windy weather conditions can make an accurate UAV-waypoint nadir-flight impossible. Even images that were taken at the same position in a very short interval of time may show significant displacements of the camera perspective (Lo Brutto, Borruso and D'Argenio 2012). This may result in the difficulty to achieve the necessary level of geometric orientation and overlap between single images. In contrast to this conventional practice, our approach is to replace the monoscopic camera by a calibrated stereoscopic camera, commonly referred to as '3D stereo camera'. The main objective of this study is to evaluate to what extent the combination of a quadrocopter and such low-cost digital stereo camera is able to produce stereoscopic evaluable sets of aerial photographs for the (3D-) documentation of archaeological geostructures.

\section{SYSTEM SET UP}

The archaeological excavation site in Doliche that served as a testing area for our field study is located in South East Turkey (Province of Gaziantep) and covers approximately $10.000 \mathrm{~m}^{2}$ at the summit region of Mt. Dülük Baba Tepesi. For our purpose of taking aerial images of this site we chose a small, flexible UAV that is easy to handle and transport. Equipped with a small digital stereo camera, aerial images with high resolution can be obtained from various altitudes and analysed later on.

\subsection{UAV}

Unmanned Aerial Vehicles (UAVs), also called Unmanned Aerial Systems (UASs) or drones are basically aircrafts without a pilot onboard. They may however be radio controlled by a pilot on the ground or fly autonomously along a previously programmed route. There are a variety of UAVs differing in size, shape, weight, possible time of flight, load capacity and fields of application. The wide range of their potential photogrammetric applications has been verified in different studies. In particular, it has been shown that UAV-platforms with attached digital cameras are very well suited for aerial surveys of archaeological sites (e.g. Eisenbeiss et al, 2005).

The UAV we used for our study needed to be light-weight, relatively small and easy to transport, capable of carrying the stereo camera, which weights about $250 \mathrm{~g}$, mounted to a servo- 
driven bracket. For these reasons we chose a self-built Quadro XL (MikroKopter, 2012a) equipped with a modified landing skid and a servo-driven camera bracket (Figure 1). The copter is propelled by four rotors. It has a diameter of $60 \mathrm{~cm}$ and a load capacity of up to $1 \mathrm{~kg}$. It was radio controlled from the ground using a Spektrum MX-20 RC.

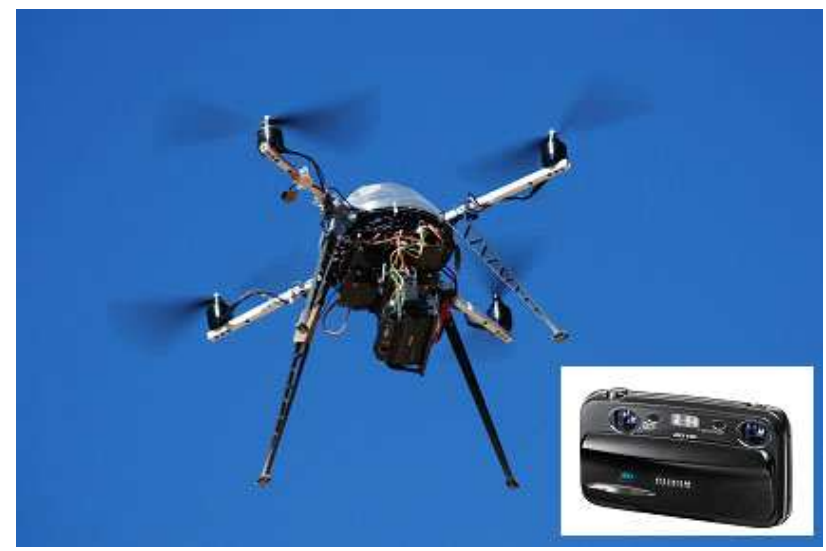

Figure 1. MikroKopter (Quadro XL) with the attached Fuji FinePix Real 3D W3 stereo camera during a flight mission at the survey site Doliche (photo by R. Dylka, 2012)

\subsection{Stereoscopic Camera}

The camera applied in our ongoing study is the FinePix Real 3D W3, manufactured by Fuji Company (Fujifilm, 2013). It was launched on the market in 2010 as a low-cost digital stereo camera for amateur photographers. It represents a small-format and light-weight stereoscopic digital camera which is equipped with two parallel lenses able to acquire two images simultaneously with a defined stereo-overlap of at least $90 \%$ at a digital resolution of 10MP. The images data can be stored as a single MPO (Multi Picture Object) file or as two different JPEG files.

Table 1. Specifications of the Fujfilm Finepix Real 3D W3 stereo camera

\begin{tabular}{|l|l|}
\hline Number of effective pixels & 10.17 megapixels \\
\hline CCD Sensor & $2 \times 1 / 2.3$ " CCD \\
\hline Lens & $\begin{array}{l}\text { Fujinon, F3.7-4.2, } \\
\text { focal length 6.3-18.9mm }\end{array}$ \\
\hline Sensor size & $\begin{array}{l}\text { 6.16mm x 4.62mm } \\
\text { (Bockaert, 2013) }\end{array}$ \\
\hline Baseline & $75 \mathrm{~mm}$ \\
\hline $\begin{array}{l}\text { Number of recorded pixels } \\
\text { (L 4:3) }\end{array}$ & 3648 x 2736 pixels \\
\hline Storage media & SD memory card \\
\hline Power supply & NP-50 Li-ion battery \\
\hline Dimensions & $\begin{array}{l}\text { approx. 124.0 (W) x 65.9(H) } \\
\text { x 27.8 (D) mm }\end{array}$ \\
\hline Weight & $\begin{array}{l}\text { approx. 250g (including } \\
\text { battery and memory card) }\end{array}$ \\
\hline
\end{tabular}

The stereo-concept of the Finepix 3D W3 equates to the principle of stereoscopic viewing with human eyes. As a consequence, a geo-object is imaged from two different perspectives resulting in two corresponding but slightly different photos: One point on the ground is projected under a certain convergence angle, latter one depending on the base line between the lenses, the flight altitude and the height of the objects. The differences between several angles result in different distances of the points on each image. Instead of measuring the Z-value of the points, the disparity of the distances of the points' projections, the stereoscopic parallax, is measured and hence creates the depth perception (figure 2).

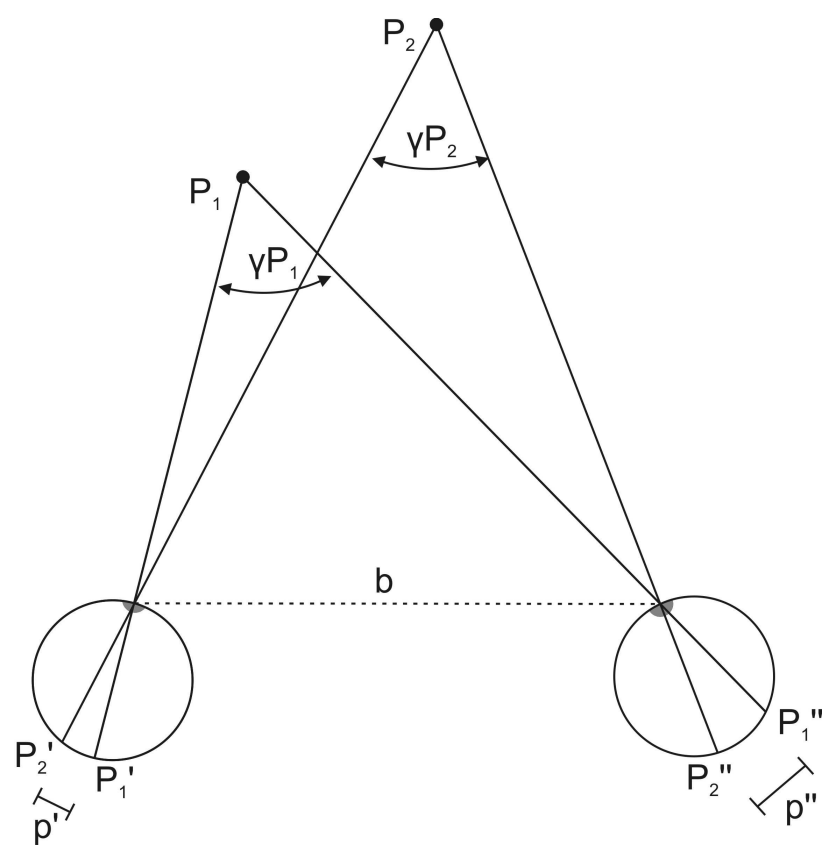

Figure 2. Principle of stereo viewing with a 3D camera:

$\mathrm{b}=$ baseline, distance between the camera's lenses;

$\mathrm{P} 1$ and $\mathrm{P} 2=$ two points of an object; $\mathrm{P} 1^{\prime}$ and $\mathrm{P} 2{ }^{\prime}=$ projections of $\mathrm{P} 1$ and $\mathrm{P} 2$ on the left lense; $\mathrm{P} 1 "$ and $\mathrm{P} 2 "$ = projections of $\mathrm{P} 1$ and $\mathrm{P} 2$ on the right lense; $\mathrm{YP} 1$ and $\mathrm{YP} 2=$ convergence angles; p"- p' = stereoscopic parallax (modified after Albertz, 2007)

Each twin-set of images exhibits strictly defined geometric parameters that were determined in detail by a laboratory calibration. A three-dimensional array of 91 control points was photographed from different positions. Focal length was set to minimum zoom/widest angle. Since the focus of the Fujifilm FinePix Real 3D W3 cannot be set to infinite, it was set to automatic mode. The images were analyzed using Pictran-B (technet GmbH, 2009). Brunn and Hastedt (2011) have pointed out that two corresponding images taken with the Fujifilm FinePix Real 3D can be utilized for photogrammetric purposes like the creation of orthophotos or extraction of 3D information. The calibrated camera was mounted under the UAV and connected to its Flight Control board, enabling a remotely controlled release of the camera and the vertical positioning of the instantaneous field of view (IOF). During the flight the camera was hold in a nadir position by the servo-driven camera bracket. Using the MikroKopterTool (MikroKopter, 2012b) the camera triggered continuously after the start of the motors, so that a stereo image set was produced every 4.6 seconds.

\section{FIELD WORK}

The flight campaign was carried out in autumn 2012 in South East Turkey, close to the ancient village of Doliche (Gaziantep Province) where an archaeological site on the summit of Mt. Dülük Baba Tepesi is been excavated and documented by a Turkish-German archaeologist team since 2001 (Winter and 
Blömer, 2006). In ancient periods, the Doliche region has been famous as the homeland of the roman god Iupiter Dolichenus, who especially gained popularity in the Roman Empire during the first three centuries AD. It has been verified that the main sanctuary of Iupiter Dolichenus was located on top of Dülük Baba Tepesi (Blömer and Winter, 2006).

In the past years this site has served as a location for some interdisciplinary archaeological work focussing also on geodata processing, image acquisition, GIS-technologies and the interpretation of close range high resolution aerial images acquired by a balloon-mounted digital remote sensing camera system (Lasar, 2008; Krüger, 2009; Prinz, Lasar and Krüger, 2010). In Turkey, the recording and acquisition of aerial images is restricted by military law and it is difficult to obtain permissions for surveying flights with planes. Alternate ways of gathering aerial images, as with a UAV, are much more practicable.

UAV flights were carried out on seven days between $11^{\text {th }}$ and $22^{\text {nd }}$ September 2012. Prior to the flight missions full ground control points (including X, Y and Z-values) were put down and picked up with a GPS total station so that the corresponding aerial images could be oriented using the control points' coordinates later on. In total more than 460 control points were distributed over the area. Due to the choppy wind conditions on the mountain Dülük Baba Tepesi (1.211m a.s.l.) flights were mainly performed during the calmer morning hours. One flight could last up to twenty minutes before the copter's batteries had to be changed. The attached stereo camera was oriented towards the ground and hold in a nadir-position by the servo-driven camera bracket. Most of the camera's settings were adjusted to the settings as they had been defined when the camera was calibrated in the lab.

Table 2. Settings of the Fujifilm Finepix Real 3D W3 stereo camera

\begin{tabular}{|l|l|}
\hline Image size & L 4:3 \\
\hline Image quality & Fine \\
\hline Zoom & $\begin{array}{l}\text { Minimum zoom } \\
\text { (widest angle) }\end{array}$ \\
\hline Focus & Auto (center) \\
\hline Sensitivity & 800 ASA \\
\hline Flash & Off \\
\hline White balance & Auto \\
\hline Shutter speed & Auto \\
\hline
\end{tabular}

After the start of the rotors, a stereo image was taken every 4.6 seconds and saved as an MPO-file that was later unpacked to individual sets of two corresponding JPEG-files. Pictures that were taken during take-off or landing procedures were excluded from further analysis. After all 425 appropriate stereo image pairs remained.

\section{IMAGE PROCESSING AND DATA ANALYSIS}

The 3D-image analysis was performed using ERDAS LPS/Stereo Analyst (ERDAS Imagine, 2012). Since the inner orientation of the camera was known due to the calibration report we used the ground control points' coordinates to perform an aerial triangulation in order to determine the exterior orientation parameters of the images and to eliminate radial distortions. This procedure included an automated extraction of a digital terrain model (DTM). Exploiting this model, further quantitative analysis is possible, including manual or automated measuring and mapping of unknown point coordinates, heights, distances, areas and volumes (Aber, 2010). Furthermore we used the DTM as input data for the orthorectification of the images and thus were able to create geometrically corrected orthophotos (Figure 3). Such images may now be used for different documentation purposes, e.g. as geobase maps in a GIS environment, combined with corresponding thematic map layers such as strata findings or other relevant archaeological information. Lasar (2008) has previously shown that such close range orthoimages yield additional crucial information, especially if used as 'time slots' within time-spatial considerations of the ongoing excavation progress (monitoring).

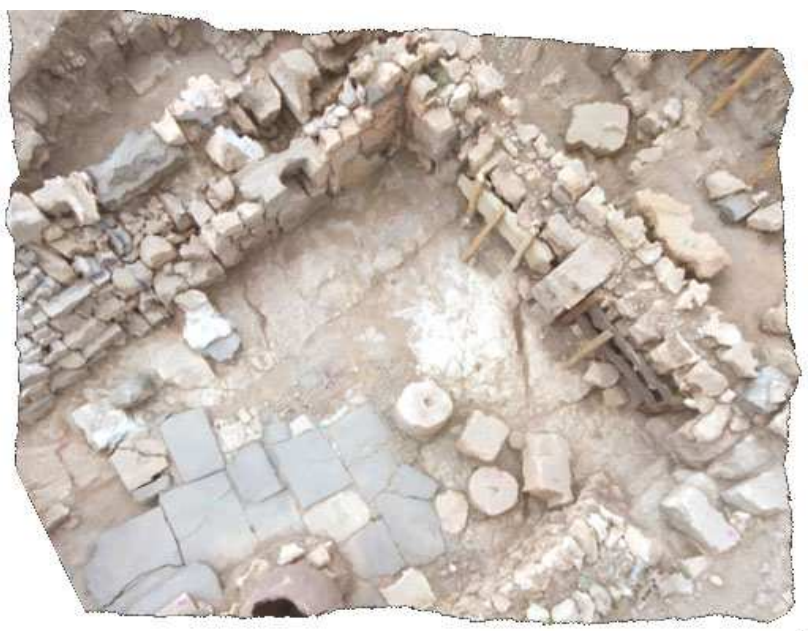

Figure 3. Orthophoto mosaic (rotated) of ca. $70 \mathrm{~m}^{2}$ of the excavation site in Doliche derived from a digital terrain model that was created out of a stereo image pair

A commonly used way to reveal a stereoscopic impression and to view the excavation site as a three dimensional scene is to display the stereo image pair as one anaglyph 3D image by combining the corresponding two images in a shifted cyan/red mode (Figure 4). By using cyan/red glasses, it is now possible to view the excavation site as a three dimensional scene and to carry out dimensional measurements without any further image processing. We also successfully used ERDAS Stereo Analyst to perform a three-dimensional extraction of single geo-objects like ashlar rocks out of the anaglyph 3D images (Figure 5).

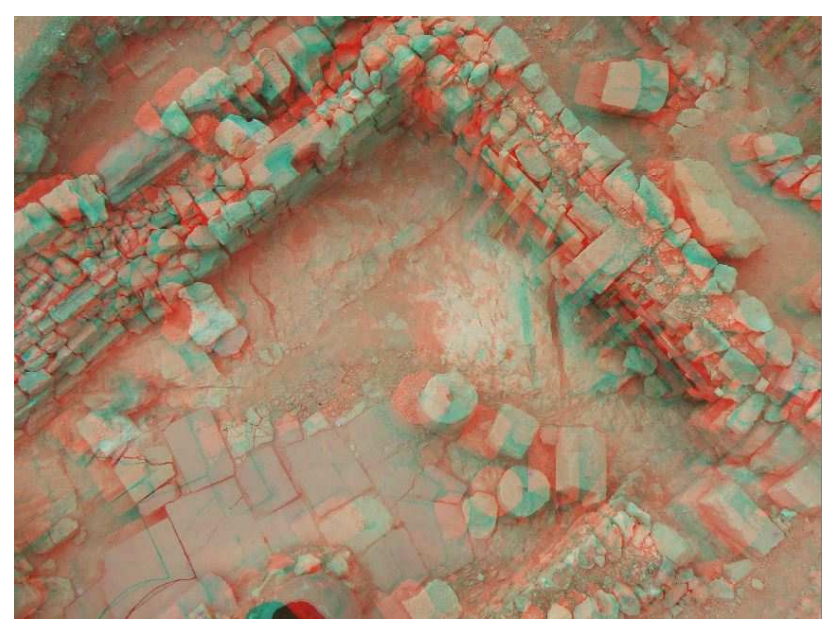

Figure 4. UAV-based anaglyphic stereo image pair (cyan/red) at Doliche displayed as anaglyph 3D image 

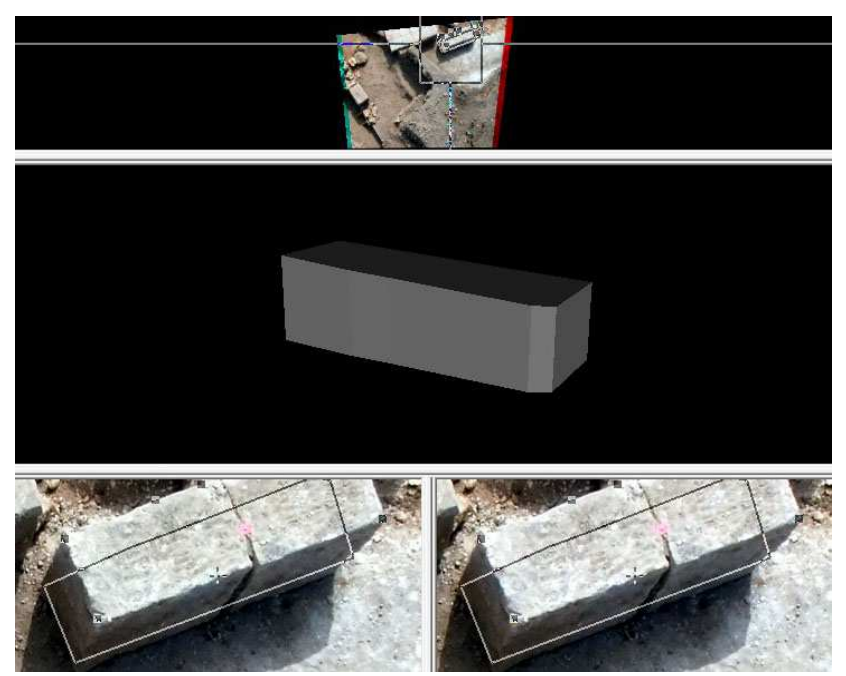

Figure 5. 3D measurement and extraction of an ashlar rock from UAV-based anaglyph 3D images at Doliche (ERDAS Stereo Analyst)

\section{DISCUSSION}

The analysis has shown that stereo image pairs obtained by a calibrated UAV-based low-cost stereo camera system can be used to create digital terrain models and orthophotos that may serve for a variety of further archaeological purposes. Even the 3D extraction of single geo-objects can be realized with the obtained images. As a consequence of the limited photobase of the stereo camera, the resulting base-height-ratio and the increasing ground sample distance with increasing flight altitude, however, one has to state that the accuracy of the outcomes directly depends on the UAV flight altitude: Differences in height can be much better perceived if the flight altitude is low. Small-scaled images are therefore much more vulnerable for errors in $\mathrm{Z}$-values. We observed that the lower a stereo image flight campaign was conducted, the better the three-dimensional quality/resolution of the calculated surface models becomes.

One traditional way of archaeological documentation is to draw the position of geo-objects at the excavation site by hand. To assure the geometric accuracy of these drawings, points are continuously picked up with a total station. Even though this is a very time-consuming technique it is reasonable to assume that it is also very accurate. We used these drawings as a reference and overlaid our orthophotos with them using ArcMap 10.1 (ESRI, 2012). It becomes obvious that orthophotos derived of stereo image pairs that were taken at a low flight altitude have a smaller offset than orthophotos that derived of stereo image pairs that were taken at a higher altitude (Figures 6 and 7). We therefore can conclude that the quality of our orthophoto (which depends on the quality of the DTM) declines with the shooting distance. This means the lower the flight altitude is, the better the accuracy of the surface model and the orthophoto becomes.

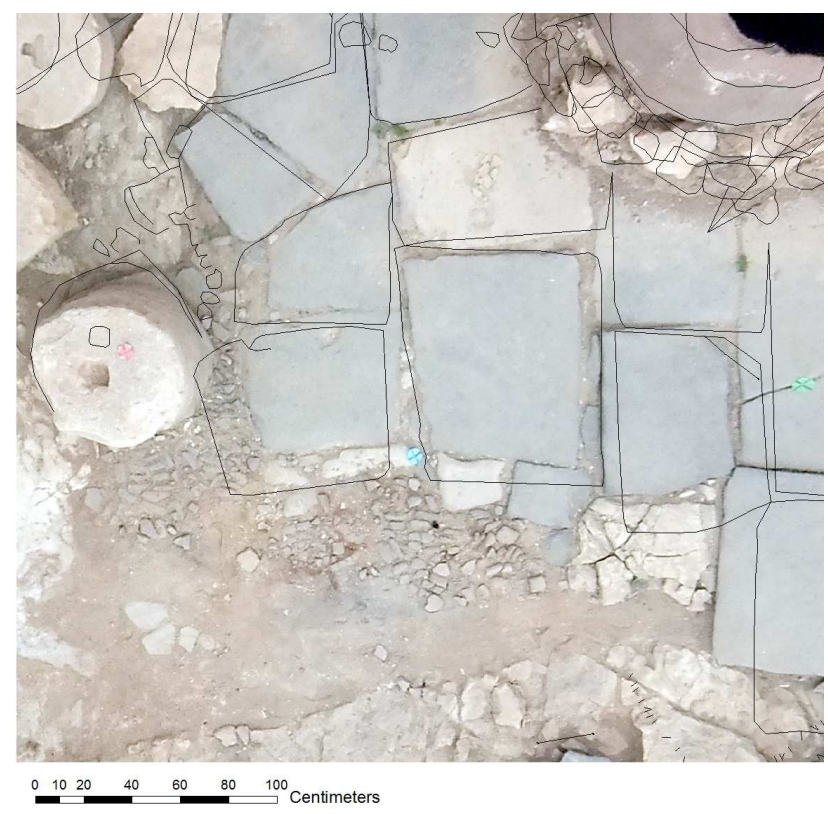

Figure 6. Detail of an orthophoto with overlaid drawings. Flight altitude was approx. $12 \mathrm{~m}$; the photo reveals an offset of up to $20 \mathrm{~cm}$.

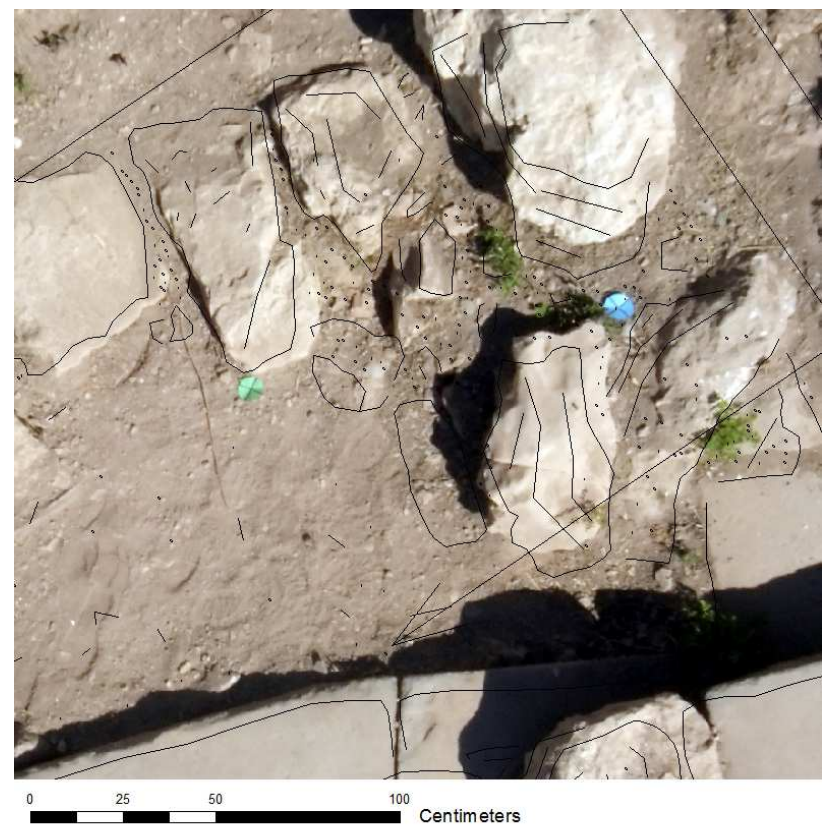

Figure 7. Detail of an orthophoto with overlaid drawings. Flight altitude was approx. $6 \mathrm{~m}$. The DTM's and thus the orthophoto's accuracy rise considerably with lower flight altitude (note the two green and blue ground control points).

One has to obtain a reasonable compromise between the desired accuracy and the area that can be covered by one stereo image pair. This can only be decided upon the concrete use case. Further research will have to show to what extent the quality of the DTMs may be improved by adding more ground control points.

As Eisenbeiss, 2009 has observed, not all commercially available software packages for image processing can be used in all possible photogrammetric applications of UAVs, since most of them are designed for standard aerial images. Some studies have explored the possibilities of alternate, free and low cost 
software that for example make use of structure-from-motion techniques (Neitzel and Klonowski, 2011). Further research will have to evaluate the possibilities of these computer vision techniques to perform the image processing with image pairs obtained from a UAV-based stereo camera.

Possible applications for the technique of using a UAV-based low-cost stereo camera system may however go beyond archaeology. One imaginable example is the digital representation of city structures and the visualization of planned architectural changes where the relation of different buildings is much more important than their accurate position.

Another use case could be the usage of stereo image pairs for the creation and digital representation of time series to monitor ongoing social-spatial processes for geographical analysis, e.g. in remote villages, where up-to-date aerial images with high resolution are not available. Here again, the exact positions of geo-objects are less important than the observation of their general structures and their change over time. Thus, our approach can serve as a fast, cost-effective and flexible way for the production of geometrically predefined stereo image pairs even under challenging weather conditions.

\section{CONCLUSION}

Our study has shown that a UAV-based low-cost stereo camera system is able to produce stereoscopic evaluable sets of aerial photographs that can be used for the documentation of archaeological geo-structures. If the inner orientation of the camera is known and the outer orientation can be determined by ground control points, a digital terrain model (DTM) and orthophotos can be generated out of stereo image pairs. The $3 \mathrm{D}$ extraction of single geo-objects is possible as well. We therefore conclude that the combination of an Unmanned Aerial Vehicle and a stereo camera bears a high potential for the geocoded documentation of archaeological surface structures and geoobjects during ongoing excavation and survey stages. It can indeed serve as a promising alternative to conventional monoscopic systems, since the major problem of latter imaging set up is the (scale depending!) large amount of resulting single images and the laborious calculation of their individual orientation. Even though due to the limited geometric photobase of the stereo camera lower flight altitudes result in better three-dimensional qualities, the main advantage of our approach is the possibility to produce collections of geometrically predefined stereo image pairs instantaneously.

\section{REFERENCES}

Aber, J. S., Marzolff, I. and J. Ries, 2010. Small-Format Aerial Photography. Principles, Techniques and Applications. Elsevier, Amsterdam.

Albertz, J., 2007. Einführung in die Fernerkundung: Grundlagen der Interpretation von Luft- und Satellitenbildern. 3rd edition. Wissenschaftliche Buchgesellschaft, Darmstadt.

Blömer, M. and E. Winter (eds.), 2012. Iuppiter Dolichenus. Vom Lokalkult zur Reichsreligion. Mohr Siebeck, Tübingen.

Brunn, A. and H. Hastedt, 2011. Untersuchung der Fujifilm Real 3D Stereokameras für den photogrammetrischen Einsatz. Oldenburger 3D-Tage 2011, 8p. (extended abstract).
Bockaert, V., 2013. Glossary: Sensor sizes, http://www.dpreview.com/glossary/camera-system/sensor-sizes (28 March 2013).

Eisenbeiss, H., K. Lambers, M. Sauerbier, L. Zhang, 2005. Photogrammetric documentation of an archaeological site (Palpa, Peru) using an autonomous model helicopter. In: The International Archives of the Photogrammetry, Remote Sensing and Spatial Information Sciences, Torino, Italy, Vol. XXXIV5, part C 34, pp. 238-243.

Eisenbeiss, H., 2009. UAV photogrammetry. Diss. ETH No. 18515, Institute of Geodesy and Photogrammetry, ETH Zurich, Switzerland, Mitteilungen Nr.105.

ESRI Inc, 2012. ArcMap Version 10.1.

ERDAS Imagine, 2012. LPS \& Stereo Analyst. Leica Photogrammetry Suite, Vers. 10, ERDAS Inc. (USA).

Fujifilm, 2013. FinePix REAL 3D W3, http://www.fujifilm.com/products/3d/camera/finepix_real3dw3/ (16 March 2013).

Kraus, K., 2007. Photogrammetry. Geometry from Images and Laser Scans. Walter de Gruyter, Berlin/New York, p.134.

Krüger, K.-P, 2009. Landschaftswandel der türkischen Euphratregion (1969-2004) unter Berücksichtigung des Südostanatolien-Projektes - Eine multitemporale, multisensorale Fernerkundungsanalyse anhand von Fallbeispielen der Provinzen Gaziantep und Urfa. Dissertation. Münster, WWU Münster, Institute of Geography.

Lasar, B., 2008. Konzeption, Entwicklung und Erprobung eines Fernerkundungssystems zur Generierung hochauflösender Geobasisdaten am Beispiel der archäologischen Grabungsstätte Doliche (Südosttürkei). Diploma thesis, WWU Münster, Institute of Geography.

Lo Brutto, M., A. Borruso and A. D'Argenio, 2012. UAV Systems for Photogrammetric Data Acquisition of Archaeological Sites. In: International Journal of Heritage in the Digital Era. 1.Supplement 1, pp. 7-14.

MikroKopter, 2012a. MK Basisset Quadro XL Starter, https://www.mikrocontroller.com/index.php?main_page=produ ct_info\&cPath=80\&products_id=731 (16 March 2013).

MikroKopter, 2012b. MikroKopterTool, http://www.mikro kopter.de/ucwiki/MikroKopterTool (23 March 2013)

Neitzel, F. and J. Klonowski, 2011. Mobile 3D mapping with a low cost UAV system. In: The International Archives of the Photogrammetry, Remote Sensing and Spatial Information Sciences, Zurich, Switzerland, Vol. XXXVIII-1, part C 22, pp. 39-44.

Prinz, T., Lasar, B. and K.-P. Krüger, 2010. High-Resolution Remote Sensing and GIS Techniques for Geobase Data Supporting Archaeological Surveys: A Case Study of Ancient Doliche, Southeast Turkey. In: Geoarchaeology, 25/3 (Wiley and Blackwell; Oxford, New York), pp. 352-374.

technet GmbH, 2009. Pictran-B. Version 5.1. 
Winter, E. and M. Blömer, 2006. Eine antike Stadt an der Nahtstelle der Kulturen. Ein Führer durch das antike Stadtgebiet und das Heiligtum des Iupiter Dolichenus. Nurol Matbaacılık ve Ambalaj Sanayi A.S., Ankara.

\section{ACKNOWLEDGEMENT}

The work presented in this paper was developed in close cooperation with the "Forschungsstelle AsiaMinor" of the University of Münster, Germany. The authors would like to thank Prof. Dr. Engelbert Winter and his team for the possibility to join the survey in Doliche at several occasions. Furhermore we are grateful for support by Dr. Michael Blömer and Torben Schreiber M.A. during the field work. Prof. Dr. Ansgar Brunn (University of Applied Sciences Würzburg-Schweinfurt) has to be acknowledged for his collaboration and the calibration of the stereo camera. 